\title{
Increased mantle convection during the mid-Cretaceous: A comparative study of mantle potential temperature
}

\author{
Karen Ricciardi and Dallas Abbott \\ Lamont-Doherty Earth Observatory of Columbia University, Palisades, New York
}

\begin{abstract}
Mantle convection patterns of the past are not well known, yet an understanding of changing mantle convection characteristics is fundamental to understanding the evolution of plate tectonics. There are very few ways to examine mantle characteristics of the past. Changes in spreading rate and volcanic activity with time have been used to draw conclusions about historic changes in mantle activity. Mantle temperature has been found to be related to crustal thickness. With this relationship, crustal thicknesses may now yield new conclusions about historic changes in mantle characteristics. We have inferred changes in mantle convection patterns throughout the last $180 \mathrm{~m}$.y. by examining variations in assumed crustal thickness within the Pacific basin. Crustal thicknesses were calculated from residual depth anomalies by assuming that residual depth anomalies are the result of isostatic compensation of variations in crustal thickness. Crustal thickness is determined at the time of crustal formation and is dependent upon the temperature of the mantle source material. Intraplate hot spot volcanism effects on crustal thickness were not ignored. Examination of variations in crustal thickness of crust of different ages can reveal information about changing temperatures of the mantle at the ridge through time. We have learned that mantle temperatures at the ridge during the mid-Cretaceous were more variable than those temperatures at the ridge after the mid-Cretaceous. Furthermore, we have inferred from the data that mantle temperatures at hot spots were higher during the mid-Cretaceous than those at hot spots existing after the mid-Cretaceous. We suggest that mantle convection at the ridge was more rapid during the mid-Cretaceous causing a higher variability of temperatures at the ridge. We also note that this period of increased mantle convection is concurrent with the increased mantle temperatures at hot spots within the Pacific basin.
\end{abstract}

\section{Introduction}

Mantle convection is the process by which heat from the interior of the Earth is released at the surface of the Earth, mainly at plate boundaries. Mantle convection drives plate tectonics, although this process is not well understood. Scientists have only been able to theorize about present-day mantle convective patterns by mathematically modeling convection in different types of media thought to be similar to mantle material in convective properties. The only areas where mantle characteristics are observed directly is at ridges and active volcanos where new crust is being created. By examining temporal variations in crustal production, we infer temporal changes in mantle convective patterns.

The thickness of the crust produced at ridges and hot spots is related to the mantle's potential temperature at the time of crustal production. Potential mantle temperature is the temperature a fluid mass would have if it were compressed or expanded to some constant reference pressure. Because the interior of the upper mantle is roughly adiabatic, the in situ mantle temperature is not a good guide to differences in heat content. For this reason, potential mantle temperature is used to describe the thermal state of the mantle [McKenzie and Bickle, 1988]. Areas of mantle upwelling have higher potential temperatures, whereas areas of mantle downwelling have lower

Copyright 1995 by the American Geophysical Unjon.

Paper number 95JB02331.

0148-0227/95/95JB-02331\$05.00 potential temperatures. The potential temperature at midocean ridges and hot spots varies spatially and temporally. High potential temperatures produce a large degree of partial melting creating a large melting regime at ridges and hot spots. Large melting regimes produce thick crust, whereas small melting regimes produce thin crust [Langmuir et al., 1993]. We calculate temporal variations in oceanic crustal thickness in the Pacific basin to infer temporal changes in the distribution of potential temperature of the mantle. Changes in mantle convection are then inferred from changes in distributions of potential temperature. The distribution for the Mid-Cretaceous shows a higher mean mantle potential temperature, a higher degree of variance, and increased skewness toward higher temperatures.

The mantle's potential temperature was determined in the following manner. Pacific basin bathymetry, sediment thickness, and crustal age were sampled with a grid spacing of 30 arc min by 30 arc min true to global latitudes and longitudes. The effects of sediment loading on bathymetry were removed to determine the adjusted crustal depths. The adjusted crustal depths and crustal ages were used to determine a predictive depth versus age curve for the Pacific basin. Expected depth values based on the predicted depth versus age curve were subtracted from the adjusted crustal depths to attain residual depth anomaly values. Crustal thickness was calculated using an isostatic model which assumes that the crust and the mantle have a constant density and that the crust at the sampled grid points is in perfect isostatic equilibrium. The relationship between the mantle's potential temperature and crustal thickness has been determined based on a the- 
oretical model similar to that of White et al., where the thickness of the oceanic crust was estimated from a melt distribution derived by inversion of rare Earth element concentrations [McKenzie and Bickle, 1988; White et al., 1992]. This relationship was used to calculate potential temperature values from crustal thickness values. Changes in potential temperature distributions determined from seafloor bathymetry in the Pacific basin were used to make inferences about temporal changes in mantle convection.

Mantle convection rates and mantle potential temperatures have a complicated interdependent relationship. In a rapidly convecting mantle one can theorize how lateral heat transport might be minimized and, hence, how mantle potential temperature is an indicator of convection rates rather than the average temperature of the entire mantle. The theory is that hot mantle material is more buoyant than cool mantle material. Excess buoyancy will cause hot mantle material to rise more quickly. A rapidly convecting environment could increase lateral temperature gradients giving rise to increased lateral heat transport; however, most of the heat transported in such an environment would be vertical and the overall effects of lateral heat transport would be minimized.

It has been observed that oceanic crust created at very slowspreading ridges exhibits anomalously thin crust and small amounts of melt [White et al., 1992]. It is possible that an increase in mantle convection at the ridge may increase the amount of melt leading to the production of anomalously thick crust as well as an increase in the rate of seafloor spreading. Excess buoyancy of mantle material at the ridge may increase "ridge push", thereby contributing to an increase in spreading rate and plate velocity (Figure 1) [Forsyth and Uyeda, 1975]. The increased spreading rate caused by excess buoyancy of hot mantle material at the ridge would increase the variance of the mantle's potential temperatures along the ridge. Normal spreading at the ridge creates a mass deficiency directly under the ridge that is filled by mantle material upwelling directly beneath the ridge. When spreading rates increase, the mass
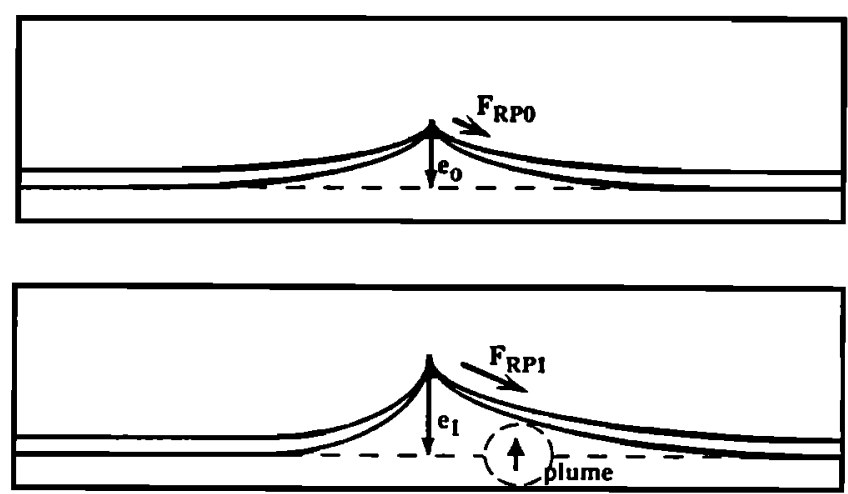

Figure 1. An increase in mantle temperature at the ridge caused by plume activity will increase the elevation of the ridge axis, e, by thermal upwelling. Plumes can increase the ridge elevation by thousands of meters, sometimes making the ridge axis subaerial, as seen in Iceland. Ridge push, FRP, one of the driving forces of plate motion, is related to ridge axis elevation by $F_{R P}=e(A+e B)$, where $A$ and $B$ are constants dependent on gravity, mantle and water density, and plate thickness [Fowler, 1990]. A rise of ridge elevation from 2635 $\mathrm{m}$ depth to $1635 \mathrm{~m}$ depth will increase ridge push by $50 \%$ (3.1E12 N/m to $4.6 \mathrm{E} 12 \mathrm{~N} / \mathrm{m}$ ).
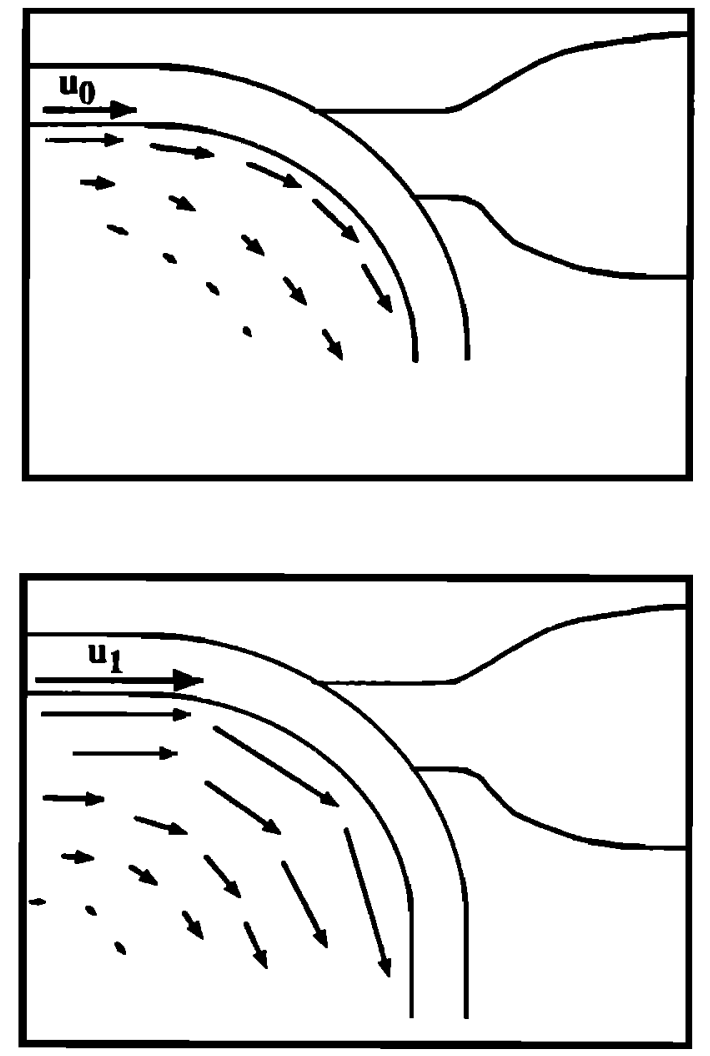

Figure 2. An increase in plate velocity, u, can increase plate subduction rate. More cool oceanic plate material subducts into the mantle, cooling off a greater amount of the hot mantle at depth. An increase in plate subduction may also increase mantle convection due to mantle drag forces which couple plate velocity to mantle flow.

deficiency increases and is filled in part by cooler mantle sources with a larger lateral extent. The input of this cool mantle material at the ridge increases the variance in the mantle's potential temperatures along the ridge. The minimization of lateral heat loss in a rapidly convecting mantle would allow the amount of melt, that is, the melting regime, at hot spots to increase thereby producing, on average, thicker oceanic crust [Langmuir et al., 1993]. Based on these theories, we have examined the distributions of the mantle's potential temperatures for given time periods in the Pacific basin to make inferences about the changes in mantle convection at the ridge through time.

An increase in spreading rate may affect overall convection in the mantle. From the increase in plate velocity during the mid-Cretaceous, we infer that convergence rates at subduction zones also increased (Figure 2) [Forsyth and Uyeda, 1975]. Mantle drag forces may prematurely drag mantle material into subduction zones. Mantle material that has not undergone sufficient cooling for subduction is being forced to undergo subduction. Less time is needed for this material to assimilate to its ambient mantle temperature at depth than mantle material that has undergone more cooling. If the assimilation time is decreased, so is the overall time it will take for that material to become part of a rising buoyant mass of material at ridges and hot spots. While this view is speculative, it is possible that overall mantle convection is affected by increases in plate velocities. 


\section{Methods and Data}

Variations in mantle potential temperature distributions of the Pacific region were determined by examining variations in residual depth anomaly values within the Pacific basin. The residual depth anomaly values are the difference between true sea depth and theoretically predicted depth based on a thermal conductive model of a cooling lithosphere. Crustal thickness values were inferred from seafloor bathymetry with the assumption that residual depth anomalies are due to variations in crustal thickness.

Residual depth anomalies, however, can also be the result of variations in mantle density which cause surface deformation in regions of mantle upwelling or downwelling. In regions of mantle upwelling, crust is underlain by hotter, lighter mantle. The mantle will push the crust upward causing the depth to basement to be more shallow than expected for its age. Mantle density heterogeneities of this nature will affect free air gravity measurements. We investigate the maximum extent to which mantle density heterogeneities may have affected seafloor depth by examining free air gravity anomalies. (The examination we have done of free air gravity is meant to provide an upper limit to the possible extent of surface deformation due to mantle heterogeneities. The investigation is not meant to make any conclusions about the patterns of mantle upwelling or downwelling under the Pacific plate. Distinguishing the patterns of mantle upwelling or downwelling requires a much more in-depth study of gravity and is not a simple problem.)

Free air gravity anomalies were sampled on a 30 arc min by 30 arc min grid of the Pacific plate [Haxby, 1987]. Free air anomalies were plotted versus assumed mantle potential temperature values determined for the same grid to determine whether residual depth anomalies caused by mantle density heterogeneities are related to residual depth anomalies caused by variations in crustal thickness (Figure 3 ). There is no

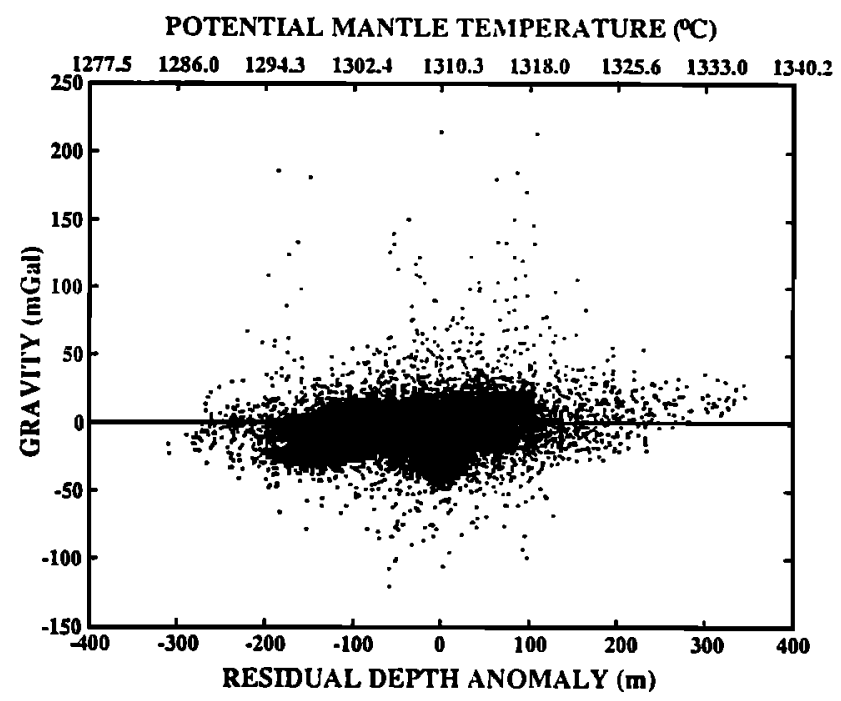

Figure 3. Plot of free air gravity anomaly values versus residual depth anomalies and potential mantle temperature for the Pacific basin. The scattered nature of this plot shows that there is no correlation between mantle heterogeneities, as inferred from free air gravity anomalies, and residual depth anomalies, as inferred from potential mantle temperature.

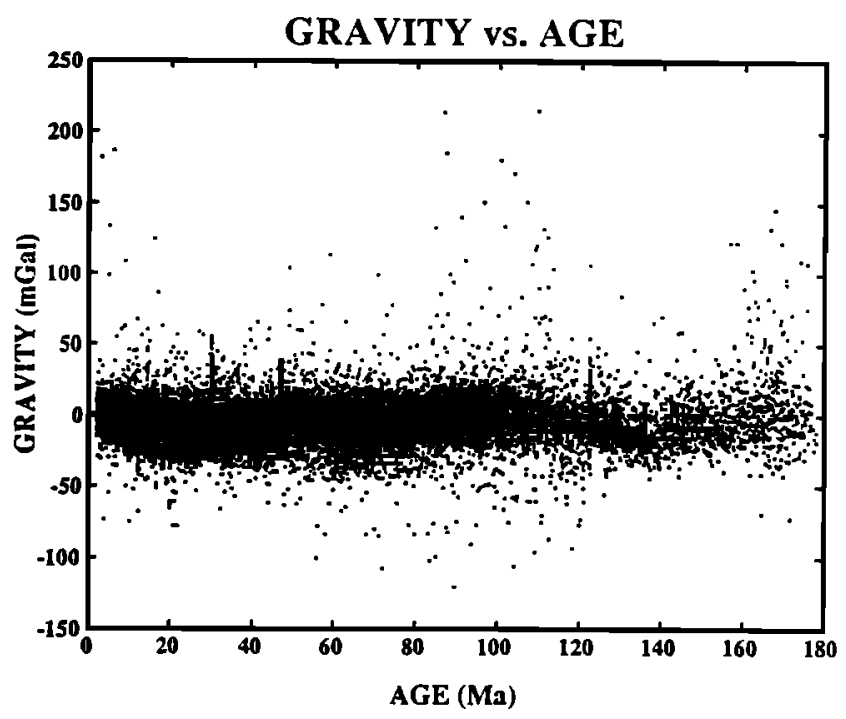

Figure 4. Free air gravity for the Pacific plate basin is plotted versus age. There are no temporal trends in the data indicating that free air gravity variations are distributed randomly in time.

correlation between residual depth and free air gravity anomalies.

Free air gravity is plotted versus age (Figure 4). No temporal trends in the gravity versus age imply that free air gravity variations (and their resultant effects on inferred crustal thickness) are distributed randomly in time. Average free air gravity anomaly values were determined for consecutive 5 m.y. bins spanning the time period represented by the Pacific plate data, 2 to $178 \mathrm{Ma}$. Likewise, average residual depth anomaly values were determined for these bins. Mantle potential temperature values were calculated from the average residual depth anomaly values.

Some variations in mantle potential temperatures could be caused by present-day mantle temperature heterogeneities. The maximum extent to which present-day mantle heterogeneities affect assumed mantle potential temperatures variations has been checked. Residual depth anomaly values were calculated from free air gravity anomaly values using the following relationship:

$$
r d a=d g /\left((2 \mathrm{p})(\mathrm{g})\left(r_{m}-r_{c}\right)\right)
$$

Residual depth anomaly, $r d a$, is measured in kilometers. Gravity anomaly, $d g$, is measured in milligals. The gravitational constant, $\mathrm{g}$, is $6.67 \mathrm{E}(-11) \mathrm{m}^{3} \mathrm{~kg}^{-1} \mathrm{~s}^{-2}$. Mantle density, $r_{m}$, and crustal density, $r_{c}$, are $3370 \mathrm{~kg} \mathrm{~m}^{-3}$ and $2860 \mathrm{~kg}$ $\mathrm{m}^{-3}$. These residual depth anomaly values were used to determine the mantle's potential temperatures. These particular temperatures represent the maximum amount to which the assumed potential temperatures, determined from true residual depth anomalies, can be accounted for by present-day mantle density heterogeneities. We have plotted both the mantle's potential temperature determined from the free air gravity data and the mantle's potential temperature determined from the residual depth anomalies versus age (Figure 5). There is no apparent correlation between these temperature values. We infer from this plot that present-day mantle heterogeneities only introduce scatter into the assumed mantle potential temperature data set. 


\section{POTENTIAL TEMPERATURE vS. AGE}

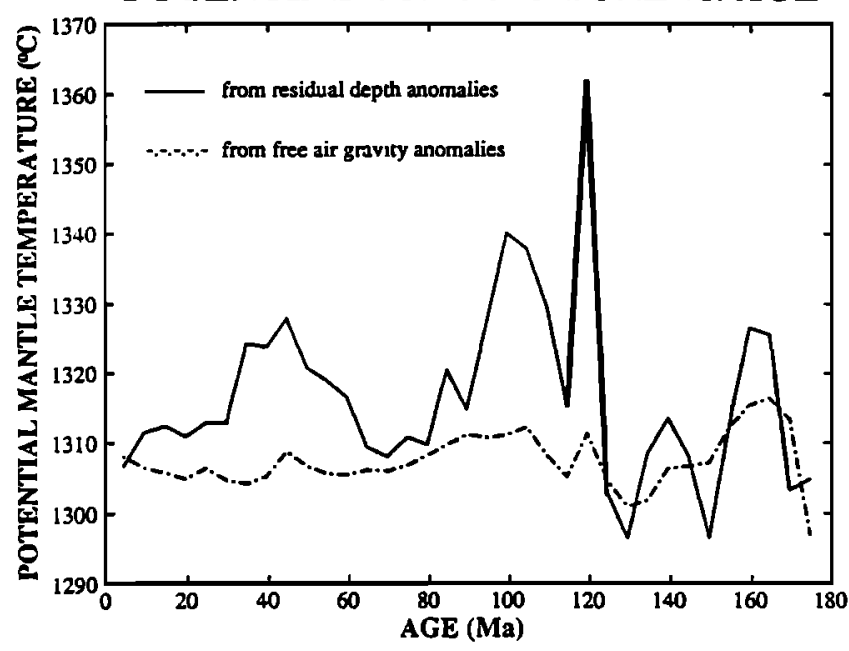

Flgure 5. Average potential mantle temperature determined from free air gravity (dotted line), and average ancient potential mantle temperature (solid line), inferred from residual depth anomalies, are plotted versus age. The averages were determined for consecutive $5 \mathrm{~m}$.y. bins from $2 \mathrm{Ma}$ to $178 \mathrm{Ma}$. These plots are not well correlated. It is unlikely that variations in residual depth anomaly are the result of variations in present-day mantle temperature.

We have assumed that residual depth anomalies in the Pacific basin are due solely to variations in crustal thickness. However, the central value of the gravity for the midCretaceous is approximately $4 \mathrm{mGal}$ higher than that for the post mid-Cretaceous (Table 1). This change in mean free air gravity anomaly of $4 \mathrm{mGal}$ corresponds to a change in the mantle's potential temperature of approximately $3.5^{\circ} \mathrm{C}$. Since the change in mantle potential temperature from today versus the mid-Cretaceous is approximately 3 times this amount, this means that mantle temperature heterogeneities of today, as recorded by free air gravity, are responsible for at most one third of the residual depth anomalies recorded in the Pacific

Table 1. Statistics for Pacific Plate Free Air Gravity Anomalies, Raw Data

\begin{tabular}{lrcc}
\hline & \multicolumn{3}{c}{ A g e } \\
& $0-83 \mathrm{Ma}$ & $83-124 \mathrm{Ma}$ & $124-178 \mathrm{Ma}$ \\
\cline { 2 - 4 } & & & \\
\hline & & & \\
Number of points & 12246.0000 & 3837.0000 & 1846.0000 \\
Mean, mGal & -4.9737 & -0.4406 & -3.7906 \\
Median, mGal & -4.4244 & -1.1374 & -6.8161 \\
Standard Deviation, mGal & 14.7051 & 19.7701 & 19.6023 \\
Standard Error, mGal & 0.13288 & 0.31916 & 0.45624 \\
& & & \\
\hline
\end{tabular}

These are statistical values determined for free air gravity anomaly distributions for the Pacific basin. The three distributions are for Pacific basin data younger than $83 \mathrm{~m} . y$. , between 83 and $124 \mathrm{~m}$.y. and older than 124 m.y. of age. The change in central value of free air gravity between the distributions for data younger than $83 \mathrm{~m} . \mathrm{y}$. and data between 83 and $124 \mathrm{~m} . \mathrm{y}$. is $-4 \mathrm{mGal}$. This corresponds to a change in mantle temperature of $-3.5^{\circ} \mathrm{C}$. This change in temperature is nominal in this study. basin. At least two thirds of the residual depth anomalies recorded today are due to variations in crustal thickness.

The scatter imposed on the data set by mantle density heterogeneities is recorded in the free air gravity data. The standard deviation of the distribution of free air gravity data for the Pacific plate is $16.56 \mathrm{mGal}$ which correlates with a standard deviation in residual depth of $0.77 \mathrm{~km}$. A standard deviation in the residual depth of $0.77 \mathrm{~km}$ corresponds to a potential temperature variation of the order of $\pm 13^{\circ} \mathrm{C}$. This observation suggests that we should be extremely cautious about inferring significance to changes in the inferred potential temperature within $\pm 13^{\circ} \mathrm{C}$.

An independent measurement of crustal thickness using seismic refraction profiles has determined that the average crustal thickness in the Pacific Ocean is $6.53 \mathrm{~km}$ [White et al., 1992]. This measurement is within the scatter imposed on our measurements of crustal thickness by the free air gravity anomalies. We have assumed an average crustal thickness of $7.1 \mathrm{~km}$, the conclusive results of White et al. [1992]. The error in our data as determined from free air gravity is $\pm 0.73 \mathrm{~km}$.

We determine crustal thickness from residual depth anomaly values by applying a simple isostatic model where variations in bathymetry are due only to variations in crustal thickness. By applying a theoretical relation between crustal thickness and the mantle's potential temperature, potential temperatures were determined. The method used is schematically summarized in Figure 6.

This study examined the variations of seafloor bathymetry with age. Both the age and bathymetry data were attained from independent sources. The age data set used in this study consists in large part of a recently compiled data set based on

\section{PACIFIC BASIN DATA SCHEME}

\section{BATHYMETRY}

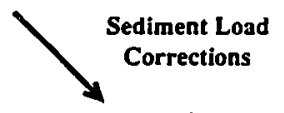

ADJUSTED CRUSTAL DEPTH

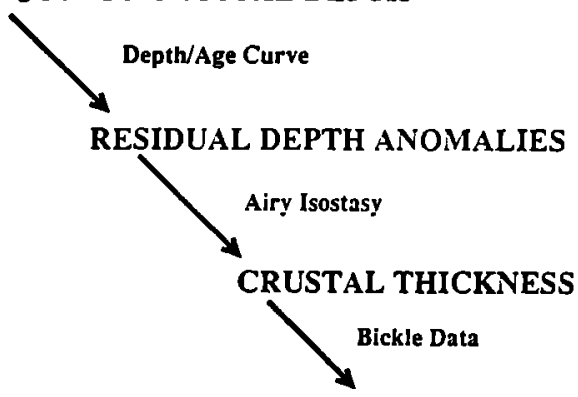

POTENTIAL MANTLE TEMPERATURE

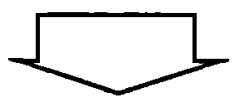

TRENDS IN

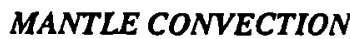

Figure 6. Scheme used to calculate potential mantle temperatures from seafloor bathymetry. The inferred potential mantle temperatures were used to examine changing trends in mantle convection. 
magnetic lineations [Muller et al., 1993]. It is complimented by the Cande et al. [1989] age data set where Muller had not yet compiled ages. Muller has since this time completed an age data set for almost the entire Pacific plate. The data set we used compares well with Muller's completed data set. Differences between the two data sets are minor and do not necessitate recalibration of the age data set used in this study.

The bathymetric data set was compiled by Smith [1990]. The methods used by Smith preserve features such as fracture zones and plate boundaries, while removing seamounts near their base. Each depth has a confidence limit of $\pm 2.5 \%$. This translates into an error in temperature of $\sim \pm 10^{\circ} \mathrm{C}$.

The bathymetry and age data sets were sampled on a 30 arc min by $\mathbf{3 0}$ arc min grid of the Pacific basin. The data was first edited by removing selected problematic points: points associated with regions very close to the ridge and regions affected by the flexural bulge at trenches. Corrections were made in the age data set for those areas immediately affected by hot spot activity after formation of the crust. The lateral region of significant crustal thickening due to hot spot magmatism lies along a $50 \mathrm{~km}$ radius about the center of the hot spot track [ten Brink and Brocher, 1987]. We used hot spot tracks based on Engebretson's plate rotations back to $145 \mathrm{Ma}$ [Engebretson and Cox, 1984]. Points within $50 \mathrm{~km}$ of a hot spot track were assigned the corresponding age of volcanism on the hot spot track.

Very young crust directly off ridge, less than $2 \mathrm{~m} . y$. of age, and crust within the flexural bulge at trenches was not considered. The flexural bulge is caused by the bending of the oceanic lithosphere as it subducts into the asthenosphere. The wavelength of the flexural bulge is dependent upon the elastic thickness of the downgoing plate. Because there exists a general relationship between the age of the oceanic crust and its elastic thickness, the elastic thickness can be calculated from the age of the lithosphere. The age of the downgoing slab, $a_{c}$. was used to calculate the flexural wavelength, $d_{b}$, for each point along the trenches surrounding the Pacific plates [Abbott and Fisk, 1986]:

$$
d_{b}=0.052 \sqrt{ }\left(\left(a_{c}\right)(3.1536 \mathrm{E} 13)\right)
$$

All points within the wavelength of the flexural bulge were not used in this analysis.

Sediment-corrected seafloor bathymetry was used to derive the mantle's potential temperatures. There is over $500 \mathrm{~m}$ of sediment cover in some areas of the Pacific basin; this significantly affects bathymetry and residual depth anomalies. Taking into account the isostatic loading affects of sediment on oceanic crust, ocean depth corrections were made to attain a data set of adjusted crustal depth. Adjusted crustal depths are the depth values that would exist if the sediments were stripped off the ocean floor. A sediment thickness database [Cazenave et al., 1986] was sampled, assigning each point on the grid a sediment thickness, $t_{s}$. Adjusted crustal depth, $D_{c}$, was calculated from sediment thickness and ocean depth, $d_{w}$, using the following equation based on perfect isostatic compensation of the sediment load [Hayes, 1988]:

$$
D_{c}=d_{w}+t_{s}\left(r_{s}-r_{m}\right) /\left(r_{w}-r_{m}\right)
$$

where $r_{s}=1900 \mathrm{~kg} \mathrm{~m}^{-3}$, average sediment density, $r_{m}=3370$ $\mathrm{kg} \mathrm{m}^{-3}$, assumed upper mantle density, and $r_{w}=1028 \mathrm{~kg} \mathrm{~m}^{-3}$, seawater density.

We determined residual depth anomalies from adjusted

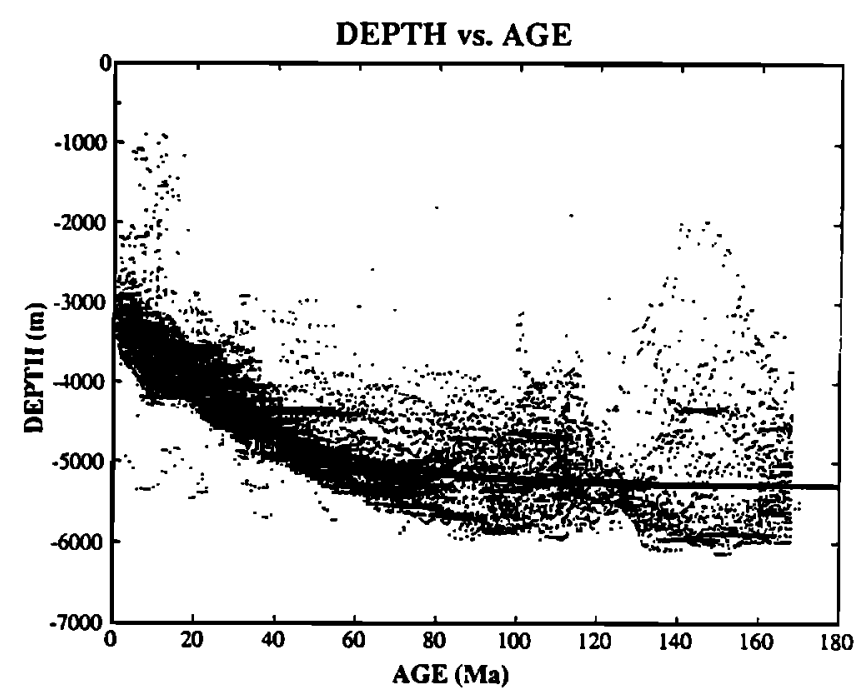

Figure 7. A depth/age curve was used to determine residual depth anomalies from adjusted crustal depth. It is based on the thermal conductive model for ages between 0 and $70 \mathrm{~m}$.y. and a best fit for ages greater than 70 m.y..

crustal depths. Depth to basement was predicted using a model that describes the relation between depth to basement and basement age. The curve was based on a thermal conductive model for those ages between 2 and $75 \mathrm{Ma}$ and a best fit for those ages greater than $75 \mathrm{Ma}$ (Figure 7) [Smith, 1990]. Smith's predictive depth, $d_{e}$, versus age curve is defined as follows:

$$
\begin{gathered}
d_{e}=2635+(307)(\text { Vage }), \quad 0<\text { age }<75 \mathrm{Ma} \\
d_{e}=5300-(2860)(\exp (- \text { age } / 28)), \quad 25<\text { age }<180 \mathrm{Ma}
\end{gathered}
$$

Depth is measured in meters and age is measured in millions of years. (Note that for ages greater than $75 \mathrm{Ma}$ it is difficult to describe the relationship between sea depth and age of the seafloor. This depth versus age curve for older ages is a best fit model for the Pacific basin. It does not assume a particular preferred model for old seafloor depths in terms of age.) Expected depths predicted by the curve were subtracted from the adjusted crustal depths to attain residual depth anomalies.

Crustal thickness values were calculated from residual depth anomalies by applying an isostatic model where variations in topography are due solely to variations in crustal thickness. A simplified version of Schubert and Sandwell's [1989] equation for crustal thickness is used to determine crustal thicknesses, $T_{c}$ from the residual depth anomalies. Crust is assigned an average density of $2860 \mathrm{~kg} \mathrm{~m}^{-3}, r_{c}$, upper mantle an average density of $3370 \mathrm{~kg} \mathrm{~m}^{-3}, r_{m}$, seawater an average density of $1028 \mathrm{~kg} \mathrm{~m}^{-3}, r_{w}$, and average crustal thickness a value of 7.1 $\mathrm{km}, T_{a}$. The following equation was used:

$$
T_{c}=\left\{\left(r d a *\left(1+\left(r_{c}-r_{w}\right) /\left(r_{m}-r_{c}\right)\right)\right) / 1000\right\}+T_{a}
$$

The residual depth anomaly, $r d a$, is measured in meters and crustal thickness in kilometers. The resulting conversion is $-218 \mathrm{~m}$ of residual depth anomaly for a kilometer of crustal thickness.

The relationship between crustal thickness and mantle potential temperature is based on experimental data initially compiled by Bickle and modified by the rare Earth element inversion theory developed by White et al. (Table 2) 
Table 2. Mike Bickle Compiled Experimental Data

\begin{tabular}{ccc}
\hline $\begin{array}{c}\text { Potential } \\
\text { Temperature, }{ }^{\circ} \mathrm{C}\end{array}$ & $\begin{array}{c}\text { Liquidus } \\
\text { Temperature, }{ }^{\circ} \mathrm{C}\end{array}$ & $\begin{array}{c}\text { Crustal } \\
\text { Thickness, km }\end{array}$ \\
\hline 1100 & $1100^{*}$ & 0 \\
1150 & 1128 & 0.49 \\
1200 & 1158 & 1.8 \\
1250 & 1189 & 3.8 \\
1300 & 1220 & 6.4 \\
1350 & 1252 & 9.5 \\
1400 & 1284 & 13.2 \\
1450 & 1318 & 17.28 \\
1500 & 1352 & 21.6 \\
1550 & 1386 & 26.49 \\
1600 & 1421 & 31.9 \\
1650 & 1456 & 37.6 \\
1700 & 1494 & 44.3 \\
1740 & 1527 & 50.62 \\
\hline
\end{tabular}

These are the values of potential mantle temperature and liquidus temperature determined by experiments compiled by Mike Bickle. The temperature values were obtained through the melting of peridotites. Solidus and liquidus temperatures are pressure dependent. This dependence was used to determine the total amount of melt generated below a given depth in the mantle. The melt thickness corresponds to the thickness of the oceanic crust being produced. Theoretical formulas were developed to describe the relationship between crustal thickness and potential and liquidus temperature values [McKenzie and Bickle, 19881.

"Solidus.

[McKenzie and Bickle, 1988; White et al., 1992]. The resulting empirical curve is a best fit approximation to the data (Figure 8):

$$
\begin{aligned}
t_{\text {pot }}= & (6.0121)\left(\left(\ln \left(T_{c}\right)\right)^{3}\right)+(3.4131)\left(\left(\ln \left(T_{c}\right)\right)^{2}\right) \\
& +(38.080)\left(\left(\ln \left(T_{c}\right)\right)\right)+1177.3
\end{aligned}
$$

\section{THEORETICAL RELATIONSHIP}

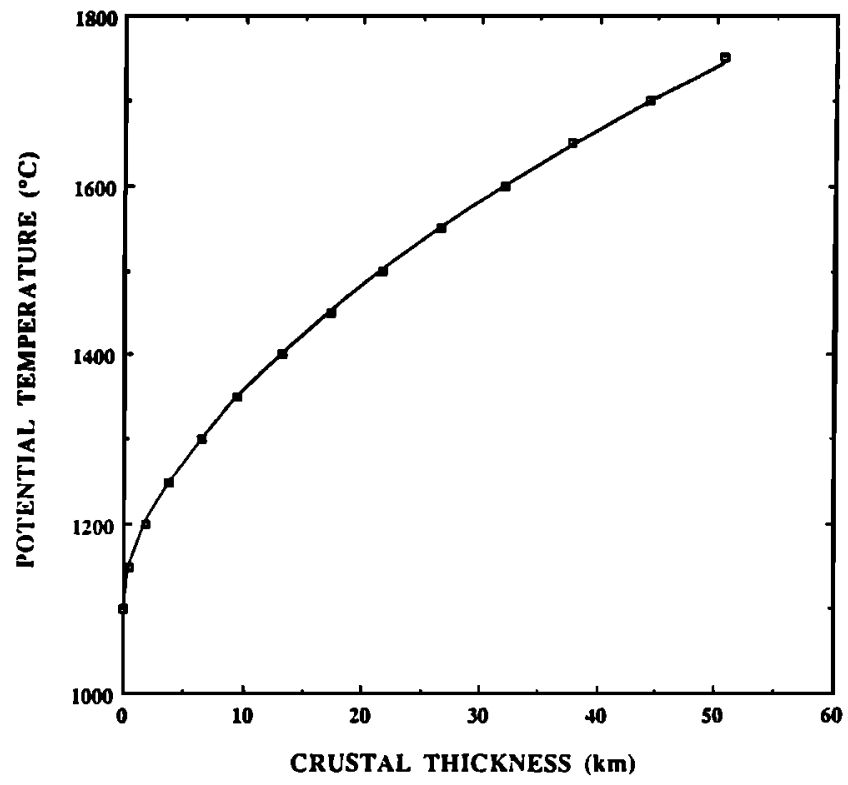

Figure 8. Graph of the crustal thickness versus mantle potential temperature from which the theoretical relationship between crustal thickness and mantle potential temperature was determined. The line is a best fit curve to the data. The potential temperature values were determined using a method based on rare earth element inversion [White et al., 1992].
Mantle potential temperature, $t_{\text {pot }}$, is measured in degrees Celsius. A thickness difference of $1 \mathrm{~km}$ correlates with a temperature change of approximately $15^{\circ} \mathrm{C}$. The result of performing these calculations was a data set consisting of a nonbiased sample of mantle potential temperatures through time.

\section{Results}

The goal of this study is to discover changes in mantle characteristics through the examination of distributions of inferred mantle potential temperatures for different time periods. Changes in these distributions have been observed. We have found that the mantle potential temperature distribution for the mid-Cretaceous (83-124 Ma) has a higher mean and a larger variance than the distribution for the time period after 83 m.y. The rise in temperature of $\sim 9^{\circ} \mathrm{C}$ is not localized to one particular region (Figure 9). The skewness of the data within a $95 \%$ confidence interval of the mean increases for the midCretaceous as compared to post $83 \mathrm{Ma}$. The mid-Cretaceous distribution is skewed toward higher temperatures, a feature not seen in the distribution for post $83 \mathrm{Ma}$.

The statistical significance of differences among the distributions was determined. The data set of mantle potential temperatures for the entire Pacific Ocean basin was broken up into $2 \mathrm{~m}$.y. time intervals. Student $t$ tests [Freund and Wilson, 1993] were performed on sequential distributions to determine significantly distinct distributions. Significant distinctions were observed between a number of sequential distributions (Table 3). Strong distinctions exist at $86 \mathrm{~m} . \mathrm{y}$. and at 122 and 124 m.y. (those distributions that have a probability of being distinct to $99.9 \%$ ). These are approximately the times defining the mid-Cretaceous quiet zone (83 to $124 \mathrm{Ma}$ ); a 41 Ma time period of no magnetic reversals. The observation of significant distinctions at 86,122 , and $124 \mathrm{~m}$.y. justifies the examination of the distributions of mantle potential temperature for the time periods before, during, and after the mid-Cretaceous quiet zone.

Variations in the distributions of mantle potential temperature during and after the mid-Cretaceous were examined. Statistical analysis was performed on the distributions using the raw data (Table 4). Histograms of these distributions are shown in Figure 10. A data set consisting of those potential temperatures within a $95 \%$ confidence interval of the mean was also examined statistically, and histograms of these distributions were made (Table 4 and Figure 10). (We believe the data set for the time period before the mid-Cretaceous is less reliable. Most oceanic crust that formed between 124 and $178 \mathrm{Ma}$ has not been preserved, and the crust that remains was affected by later volcanism. We include the statistical values and histograms in this paper for completeness.) Many features of the raw distributions of mantle potential temperature are retained in the distributions determined from data taken within a 95\% confidence interval of the mean. There are several differences among these latter distributions: the mid-Cretaceous distibutions exhibit a higher mean mantle potential temperature, a higher degree of variance, and increased skewness toward higher temperatures.

An apparent shift in mantle potential temperature occurred from the mid-Cretaceous to post mid-Cretaceous time. The central values for the mid-Cretaceous are $-9^{\circ} \mathrm{C}$ higher than the central values for the post mid-Cretaceous; $9^{\circ} \mathrm{C}$ is not statistically significant because it falls within the standard deviation of the distributions. Seismic refraction studies show no 


\section{PACIFIC PLATE}
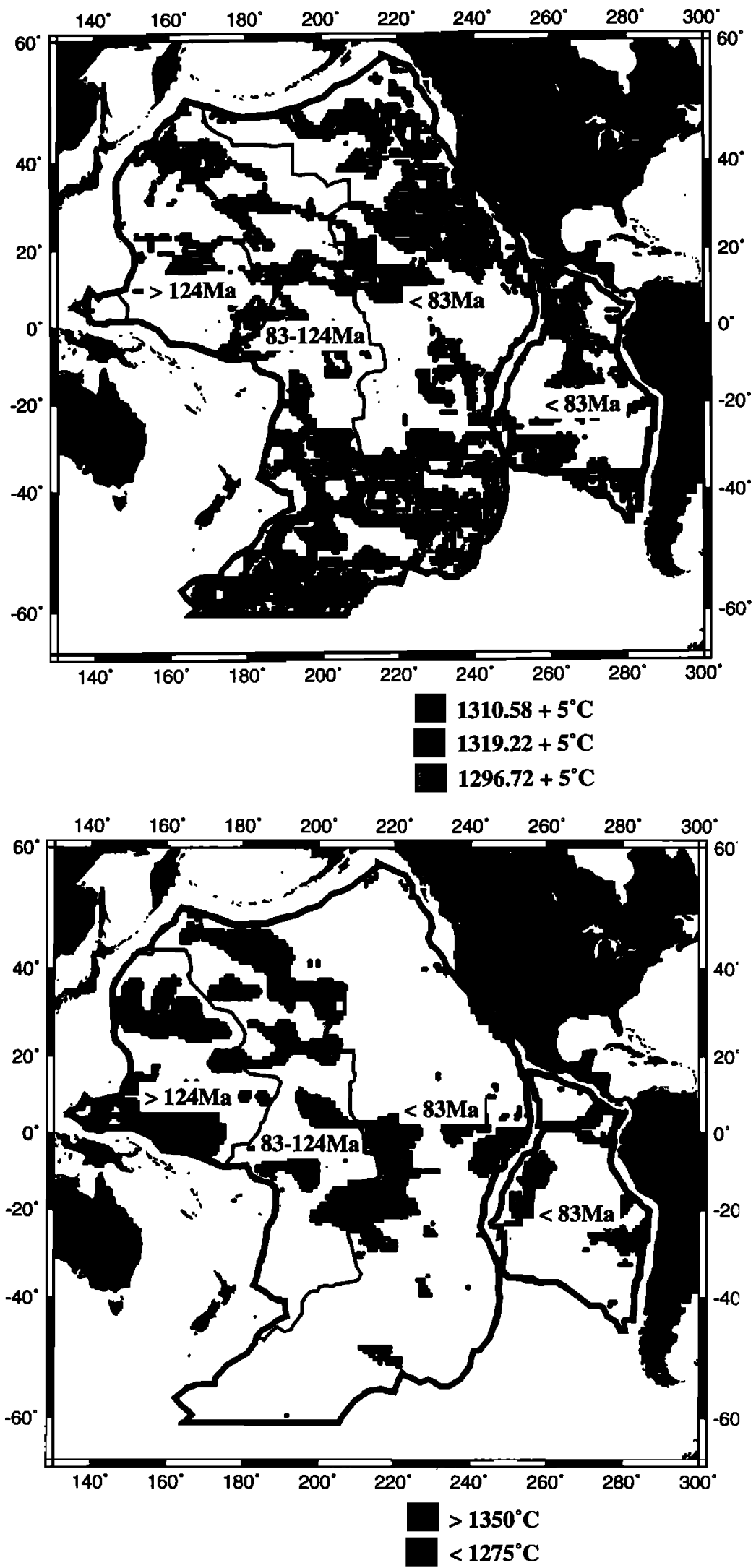

Figure 9. Maps of the Pacific basin where the study of mantle trends was conducted. (Top) Median temperatures are mapped for each time distribution, $1310.58^{\circ} \mathrm{C}$ for $0-83 \mathrm{Ma}, 1319.22^{\circ} \mathrm{C}$ for $83-124$ $\mathrm{Ma}$, and $1296.72^{\circ} \mathrm{C}$ for $124-178 \mathrm{Ma}$. (Bottom) Temperatures greater than $1350^{\circ} \mathrm{C}$ and less than $1275^{\circ} \mathrm{C}$. The median temperature of the mid-Cretaceous spans the entire mid-Cretaceous time period. They are not localized to one particular area, nor are they randomly dispersed throughout the midCretaceous. The hot areas $\left(>1350^{\circ} \mathrm{C}\right)$ also span the entire mid-Cretaceous. These regions represent off ridge hot spot volcanism. The number of hot spots did not increase during the mid-Cretaceous. Hot spots were hotter increasing volcanic productivity. 
Table 3. Statistical Values Determined for the 2 m.y. Sequential Distributions

\begin{tabular}{|c|c|c|c|c|}
\hline Age, Ma & $\begin{array}{l}\text { Number of } \\
\text { Points }\end{array}$ & Mean & Standard Deviation & $t$ Test \\
\hline 2 & 474 & 1304.67 & 23.45 & $\mathbf{0}$ \\
\hline 4 & 449 & 1304.82 & 31.79 & -0.08 \\
\hline 6 & 405 & 1303.70 & 33.59 & 0.5 \\
\hline 8 & 370 & 1304.97 & 33.31 & -0.526 \\
\hline 10 & 430 & 1307.56 & 37.12 & -1.032 \\
\hline 12 & 421 & 1308.33 & 31.53 & -0.323 \\
\hline 14 & 372 & 1312.51 & 31.45 & -1.866 \\
\hline 16 & 338 & 1311.94 & 28.12 & 0.254 \\
\hline 18 & 349 & 1313.18 & 21.75 & -0.649 \\
\hline 20 & 376 & 1310.83 & 20.62 & 1.494 \\
\hline 22 & 400 & 1311.17 & 22.36 & -0.219 \\
\hline 24 & 335 & 1309.66 & 21.09 & 0.933 \\
\hline 26 & 334 & 1309.00 & 22.61 & 0.39 \\
\hline 28 & 339 & 1310.20 & 22.87 & -0.681 \\
\hline 30 & 364 & 1316.03 & 27.62 & -3.038 \\
\hline 32 & 328 & 1310.15 & 22.82 & 3.032 \\
\hline 34 & 305 & 1308.93 & 22.65 & 0.674 \\
\hline 36 & 225 & 1325.86 & 23.36 & -8.392 \\
\hline 38 & 212 & 1324.50 & 22.73 & 0.615 \\
\hline 40 & 220 & 1323.88 & 23.75 & 0.277 \\
\hline 42 & 239 & 1325.55 & 27.34 & -0.696 \\
\hline 44 & 243 & 1321.69 & 25.23 & 1.612 \\
\hline 46 & 298 & 1333.58 & 35.33 & -4.409 \\
\hline 48 & 233 & 1323.93 & 29.14 & 3.37 \\
\hline 50 & 216 & 1321.58 & 27.88 & 0.871 \\
\hline 52 & 204 & 1321.55 & 29.22 & 0.01 \\
\hline 54 & 183 & 1319.41 & 29.85 & 0.71 \\
\hline 56 & 204 & 1317.99 & 28.61 & 0.478 \\
\hline 58 & 224 & 1319.13 & 30.05 & -0.402 \\
\hline 60 & 219 & 1319.06 & 29.22 & 0.025 \\
\hline 62 & 248 & 1317.90 & 29.3 & 0.428 \\
\hline 64 & 252 & 1314.73 & 30.75 & 1.177 \\
\hline 66 & 246 & 1314.05 & 31.14 & 0.246 \\
\hline 68 & 232 & 1310.46 & 27.5 & 1.332 \\
\hline 70 & 252 & 1306.49 & 25.92 & 1.635 \\
\hline 72 & 223 & 1306.78 & 24.9 & -0.126 \\
\hline 74 & 233 & 1307.36 & 26.88 & -0.237 \\
\hline 76 & 208 & 1309.18 & 27.71 & -0.7 \\
\hline 78 & 215 & 1310.91 & 28.84 & -0.628 \\
\hline 80 & 205 & 1311.00 & 32.9 & -0.03 \\
\hline 82 & 238 & 1308.25 & 34.11 & 0.862 \\
\hline 84 & 371 & 1308.32 & 35.87 & -0.024 \\
\hline 86 & 321 & 1317.65 & 36.13 & -3.403 \\
\hline 88 & 260 & 1320.77 & 32.92 & -1.075 \\
\hline 90 & 236 & 1321.76 & 30.52 & -0.344 \\
\hline 92 & 237 & 1316.51 & 30.88 & 1.856 \\
\hline 94 & 206 & 1313.28 & 29.57 & 1.122 \\
\hline 96 & 176 & 1315.08 & 29.45 & -0.594 \\
\hline 98 & 145 & 1324.25 & 41.67 & -2.303 \\
\hline 100 & 144 & 1338.51 & 47.13 & -2.725 \\
\hline 102 & 123 & 1339.79 & 40.34 & -0.236 \\
\hline 104 & 122 & 1341.09 & 37.27 & -0.262 \\
\hline 106 & 118 & 1340.07 & 33.75 & 0.22 \\
\hline 108 & 111 & 1339.82 & 33.09 & 0.056 \\
\hline 110 & 100 & 1338.12 & 36.51 & 0.354 \\
\hline 112 & 111 & 1335.85 & 33.59 & 0.469 \\
\hline 114 & 117 & 1326.15 & 32.58 & 2.213 \\
\hline 116 & 104 & 1325.57 & 34.88 & 0.128 \\
\hline 118 & 100 & 1313.70 & 25.47 & 2.767 \\
\hline 120 & 94 & 1313.58 & 23.95 & 0.032 \\
\hline 122 & 311 & 1394.03 & 69.09 & -11.08 \\
\hline 124 & 116 & 1312.91 & 29.57 & 12.23 \\
\hline 126 & 134 & 1307.38 & 25.51 & 1.585 \\
\hline 128 & 107 & 1303.27 & 25.4 & 1.246 \\
\hline 130 & 87 & 1301.01 & 29.11 & 0.577 \\
\hline 132 & 74 & 1298.07 & 32.6 & 0.604 \\
\hline 134 & 66 & 1294.87 & 31.45 & 0.589 \\
\hline 136 & 55 & 1298.90 & 35.24 & -0.664 \\
\hline 138 & 65 & 1301.30 & 43.49 & -0.327 \\
\hline
\end{tabular}

Table 3. (continued)

\begin{tabular}{lcccc} 
Age, Ma & $\begin{array}{c}\text { Number of } \\
\text { Points }\end{array}$ & Mean & Standard Deviation & $t$ Test \\
\hline 144 & 82 & 1315.92 & 54.85 & -0.784 \\
146 & 82 & 1315.10 & 56.44 & 0.094 \\
148 & 75 & 1306.45 & 52.53 & 0.991 \\
150 & 53 & 1306.47 & 55.88 & -0.001 \\
152 & 55 & 1301.42 & 53.67 & 0.479 \\
154 & 60 & 1294.61 & 44.77 & 0.74 \\
156 & 51 & 1299.22 & 38.95 & -0.572 \\
158 & 53 & 1311.24 & 49.74 & -1.368 \\
160 & 55 & 1320.47 & 48 & -0.981 \\
162 & 66 & 1326.87 & 43.49 & -0.768 \\
164 & 61 & 1326.53 & 44.29 & 0.044 \\
166 & 60 & 1323.70 & 44.39 & 0.35 \\
168 & 55 & 1330.14 & 41.07 & -0.805 \\
170 & 39 & 1312.68 & 37.66 & 2.101 \\
172 & 35 & 1304.46 & 24.42 & 1.099 \\
174 & 29 & 1303.10 & 14.21 & 0.245 \\
176 & 12 & 1302.00 & 11.09 & 0.226 \\
178 & 2 & 1303.25 & 5.010 & -0.152 \\
\hline
\end{tabular}

The age value is the youngest age value of the distribution it represents so, for example, a value of 2 corresponds to data between the ages of 2 and $4 \mathrm{~m} . \mathrm{y}$. The $t$ test value corresponds to the two distributions: the one within the same row as the $t$ test value and the row directly above, so, for example, the first $t$ test value, -0.08 , is the $t$ test value for the distributions for the 2-4 Ma interval and the 4-6 $\mathrm{Ma}$ interval. Distinctions to 99.9\% occur at 86, 122, and $124 \mathrm{Ma}$. The mid-Cretaceous spans the interval from 83 to $124 \mathrm{Ma}$.

Table 4. Statistics for Pacific Plate Potential Temperature Distributions

\begin{tabular}{lccc}
\hline \multicolumn{4}{c}{ Age } \\
\cline { 2 - 4 } & $0-83 \mathrm{Ma}$ & $83-124 \mathrm{Ma}$ & $124-178 \mathrm{Ma}$ \\
\cline { 2 - 4 } & \multicolumn{3}{c}{ Raw Data } \\
\multicolumn{4}{c}{} \\
Number of points & 12246 & 3837 & 1846 \\
Minimum & 1226.22 & 1249.21 & 1242.18 \\
Maximum & 1493.03 & 1515.5 & 1442.89 \\
Mean & 1313.68 & 1327.22 & 1308.84 \\
Median & 1310.58 & 1319.22 & 1296.72 \\
Standard Deviation & 29.2745 & 44.5763 & 42.3792 \\
Standard Error & 0.26454 & 0.71963 & 0.98636 \\
Skewness & 1.14969 & 1.09993 & 1.02632 \\
& & &
\end{tabular}

Data Within 95\% Confidence Interval of Mean

$\begin{array}{lcll}\text { Number of points } & 11718 & 3671 & 1759 \\ \text { Minimum } & 1255.22 & 1249.21 & 1242.18 \\ \text { Maximum } & 1372.2 & 1416.28 & 1393.51 \\ \text { Mean } & 1310.70 & 1321.49 & 1303.48 \\ \text { Median } & 1309.6 & 1317.82 & 1295.57 \\ \text { Standard Deviation } & 23.2067 & 35.8300 & 35.5564 \\ \text { Standard Error } & 0.21438 & 0.59136 & 0.84778 \\ \text { Skewness } & 0.30264 & 0.40536 & 0.79963\end{array}$

These are the statistical values for the distributions 0-83 Ma, 83-124 Ma (the mid-Cretaceous), and 124-178 Ma. Both the raw data and data within a 95\% confidence interval are shown. The central values for the mid-Cretaceous are $-10^{\circ} \mathrm{C}$ higher than the period after the midCretaceous. The variance is also higher for the mid-Crelaceous. Data for the distribution representing the time period from 124 to $178 \mathrm{Ma}$ are unreliable because the crust has been affected by later volcanism and does not retain its primitive character. We include the data for completeness. 
RA W DATA
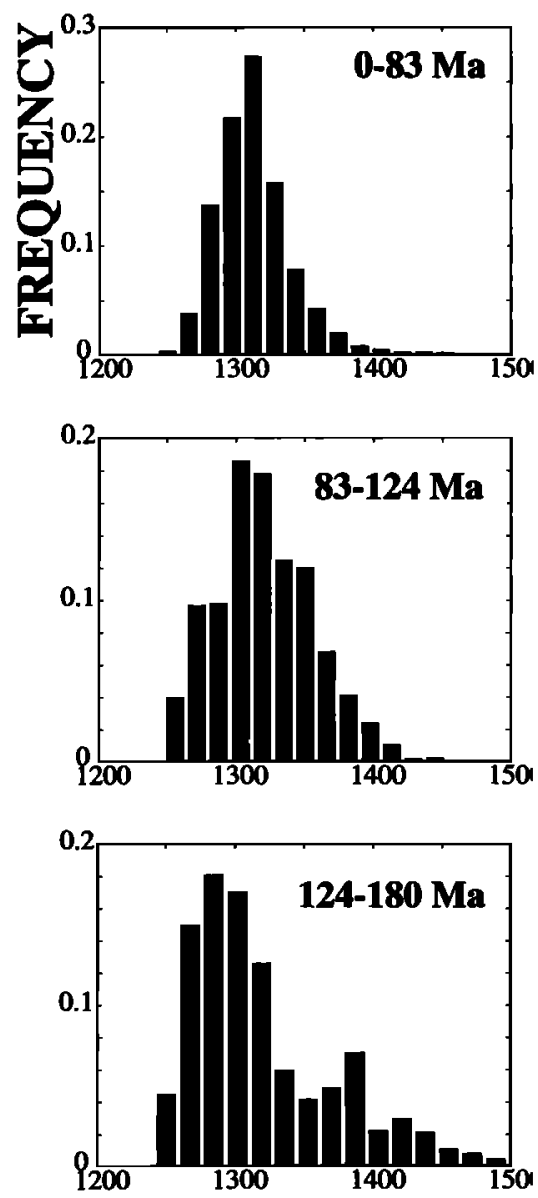

95\% CONFIEENCE
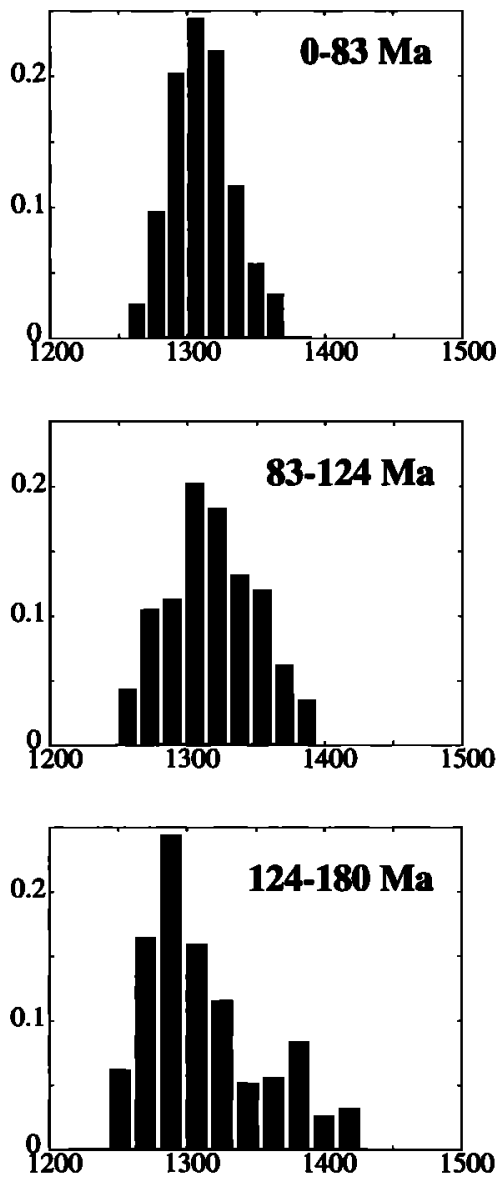

Figure 10. Histograms of potential mantle temperature distributions for the raw data as well as data within a $95 \%$ confidence interval of the mean temperature. There is an increase in median temperature of $9^{\circ} \mathrm{C}$ from the post mid-Cretaceous distribution to the mid-Cretaceous distribution. With the increase in median temperature is also an increase in variance and higher proportion of high temperatures.

significant thickening of the oceanic crust over this time interval and that crustal thickening of more than $1 \mathrm{~km}$ (correlating to an $\sim 15^{\circ} \mathrm{C}$ change in mantle potential temperature) should not be expected [Mutter and Mutter, 1993]. Recent studies of global residual depth anomalies in oceans have determined that the maximum amplitude of the dynamic topography is only about $\pm 1 \mathrm{~km}$, concurrent with seismologic studies [Kido and Seno, 1994]. Statistical analysis of the distributions of mantle potential temperature during and after the mid-Cretaceous show that mantle potential temperatures were insignificantly higher during the mid-Cretaceous than they were after the mid-Cretaceous.

We examined the shapes of both sets of histograms (Figure 10). The temperature distribution of the mid-Cretaceous has a higher variance than the distribution after the mid-Cretaceous. The high variance of the mid-Cretaceous data implies larger variations in mantle potential temperature during the midCretaceous. The histogram of the mid-Cretaceous data is skewed toward high temperature values. A greater proportion of the mid-Cretaceous temperature data has higher than expected temperature values, creating a tail toward higher temperatures in the histogram. This tail toward higher temperatures does not exist in the histogram of the post mid-
Cretaceous data. Because the tail is also present in the histogram for mid-Cretaceous data taken within a $95 \%$ confidence interval of the mean, we infer that the high temperature values of the mid-Cretaceous are representative of some phenomena occurring during the mid-Cretaceous but not after the midCretaceous. The distribution of mantle potential temperature during the mid-Cretaceous is more variable and contains a larger proportion of high temperature values than the distribution after the mid-Cretaceous.

Differences in median temperature over consecutive $5 \mathrm{~m} . \mathrm{y}$. intervals have been plotted versus time (Figure 11). Except for a few isolated jumps in temperature at 35 and $45 \mathrm{~m} . \mathrm{y}$. (possible periods of plate reorganization), the period after the midCretaceous varies little. Many rapid changes in mantle potential temperature occurred during the mid-Cretaceous. Because of the scattered nature of the data prior to the midCretaceous, the onset of the mid-Cretaceous is not clear from this plot. The end of the mid-Cretaceous, $83 \mathrm{Ma}$, is very close to $73 \mathrm{Ma}$, the time after which mantle potential temperatures fluctuate less. Thus, most of the mid-Cretaceous was characteristized by greater fluctuation of mantle potential temperatures.

The areas that represent significant differences among man- 
TEMPERATURE CHANGE vS. AGE

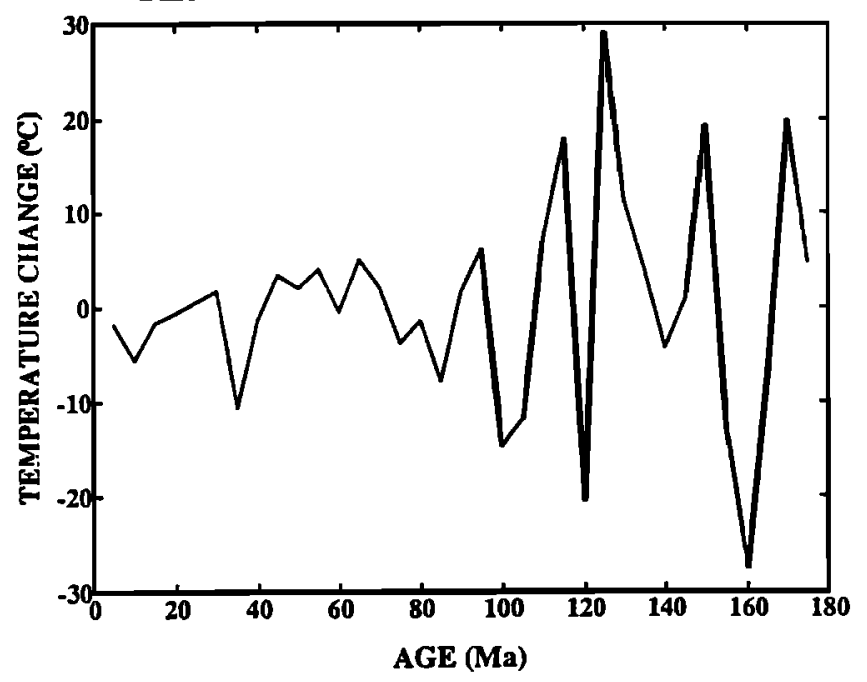

Figure 11. Plot of change in mean and median temperature over time showing that mantle temperature during the midCretaceous was not as stable as mantle temperature after the mid-Cretaceous. We infer from this that the mantle convective process of the mid-Cretaceous was more rapid.

tle potential temperatures have been mapped (Figure 9). Significant differences in mantle potential temperatures include the median values of the raw data for each time distribution, temperature values greater than $1350^{\circ} \mathrm{C}$ (the tail of the mid-Cretaceous histogram), and temperature values less than $1275^{\circ} \mathrm{C}$. The median temperature of the mid-Cretaceous is not localized to one particular area. However, the surface area distribution of the median temperature of the mid-Cretaceous is not random. The map also displays areas with high mantle potential temperatures. These hot areas span the entire midCretaceous but do not extend into the post mid-Cretaceous area. The number of hot areas per unit time during the midCretaceous is the same as that after the mid-Cretaceous. The area of the hot zones, however, is much larger during the midCretaceous. Thus, the spatial distribution of higher potential temperatures has varied through time.

\section{Discussion}

In this investigation we have found that the mid-Cretaceous is characterized by changes in the distribution of mantle potential temperature as inferred from changes in crustal thickness. The average crustal thickness produced at ridges during the mid-Cretaceous was thicker than that produced afterwards. Since the thickness of the crust is directly related to the size of the melting regime at the time of crustal production, this phenomenon is the result of higher mantle temperatures at ridges during the mid-Cretaceous. An increase in mantle convection rates is one possible explanation for this rise in temperature.

An increase in mantle convection may also explain faster seafloor spreading rates in the mid-Cretaceous. A larger than average melting regime will produce thicker than average crust [Langmuir et al., 1993]. Faster spreading has been correlated with the production of thinner than average crust at the ridge [West et al., 1994]. Both of these factors may contribute to the increase in variance of mantle potential temperatures observed in the temperature distribution of the mid-Cretaceous. An increase in mantle convection rate can affect the distribution of temperatures by minimizing lateral heat loss during upwelling, thereby facilitating the rise of higher temperature mantle material at the ridge. Faster seafloor spreading and increased volcanic productivity, characteristic of the mid-Cretaceous, are consistent with the observed mantle potential temperature distribution of the mid-Cretaceous. We infer that these mid-Cretaceous phenomena are due to an increase in rates of mantle convection.

The Ontong Java, Manihiki Plateau, and other manifestations of the Cretaceous superplume are all circa $124 \mathrm{Ma}$, that is, roughly coincident with the onset of rapid seafloor spreading in the Pacific. We propose that this increase in seafloor spreading rate of the Pacific basin was related to the uplift associated with impingement of the high-temperature plume head on the base of the Pacific plate. This uplift caused increased ridge push, which increased seafloor spreading rates. Because plates are rigid bodies, increased seafloor spreading in the Pacific also caused faster subduction rates.

An increase in the rate of subduction can affect upper mantle convection near trenches by prematurely dragging warm material in the upper mantle to greater depths within the mantle. The subducted plates are dense, negatively buoyant, and move rapidly compared to mantle upwelling driven solely by positive buoyancy. In addition, increased seafloor spreading will create a void space directly under the ridge, thereby drawing cool mantle material laterally to the ridge crest; passive upwelling increases. Therefore both downwelling regions of the mantle at subduction zones and upwelling regions of the mantle at the ridge crest will move more quickly as a result of increased spreading rate.

A statistically insignificant rise in central value of $-9^{\circ} \mathrm{C}$ has been observed for the distribution of mantle potential temperature for the mid-Cretaceous. Although this rise in temperature is small, plotting areas associated with these values can reveal information about the character of the mantle. In the determination of the median value, the effects of outlying high and low temperatures are minimized. For this reason, the central value we believe to be most representative of mantle potential temperature at the East Pacific Rise (EPR) is the median temperature. Plotting the areas associated with median temperature values we infer characteristics about mantle activity at the ridge during the mid-Cretaceous. The pattern observed in this plot (refer to observations section) may be a pattern of mantle upwelling along the ridge. If this is the case we can say that the phenomena causing the rise in median temperature for the mid-Cretaceous took place along the entire EPR and spanned the time period of the entire mid-Cretaceous.

The high temperatures that comprise the characteristic tail of the histograms for the mid-Cretaceous have also been mapped. These are areas where mantle potential temperature is greater than $1350^{\circ} \mathrm{C}$. The location of these high temperature areas is concurrent with those areas associated with hot spots and so we interpret these high temperature regions to be the result of increased volcanism at hot spots. The number of hot areas per unit time for the mid-Cretaceous is the same as the number of hot areas per unit time for the time period after the mid-Cretaceous. We interpret this to mean that hot spot formation during the mid-Cretaceous was not greater than it was after the mid-Cretaceous and that these hot areas were preexisting hot spots whose temperature rose, increasing their melting regime thereby increasing volcanic production 
[Smith, 1990]. The greater hot spot productivity (volume per unit time) of the mid-Cretaceous may be explained by an increase in mantle potential temperature at the hot spot as inferred in this study.

The mid-Cretaceous is characterized by a long magnetic normal. Larson has theorized that the cause of the midCretaceous magnetic normal was a "super-plume" originating at the core-mantle boundary [Larson, 1991b]. An increase in temperature gradient at the core-mantle boundary caused by the initiation of a "super-plume" could cause mantle convection to speed up [Larson, 1991a]. It has been argued that the relatively shallow areas in the southern portion of the Pacific basin can be explained by a superswell, a huge region of mantle upwelling [McNutt and Fischer, 1987]. While the southern volcanics could be the manifestation of the superplume suggested to be the cause of the magnetic normal [Larson, 1991b], the increased volcanism of the northern section of the Pacific basin, mid-Cretaceous in age, cannot be explained by the presence of a superswell in the south. Because the areas affected by increased volcanism span the entire mid-Cretaceous, we believe that the phenomena causing the magnetic normal of the mid-Cretaceous could also be responsible for the increase in volcanism.

The response of core/mantle boundary conductive heat flow and outer core convection to a superplume episode is as follows: The D". layer is thinned to fuel the plumes, raising its vertical temperature gradient. This raises conduction across the core-mantle boundary that in turn raises convection intensity [Larson, 1991b]. The existence of a superplume rising from the core-mantle boundary can effectively cause the increase in mantle convection rates, minimizing lateral heat transfer, thereby increasing volcanic productivity.

The potential temperature distribution of the mid-Cretaceous has a higher variance than the distribution after the midCretaceous. The mid-Cretaceous is also characterized by high and frequent fluctuations in mantle potential temperature. We interpret these factors to be an indication that mantle convection during the mid-Cretaceous was more variable relative to mantle convection after the mid-Cretaceous. The increased volume of rising plumes decreased the overall stability of mantle convection. An unstable, rapidly convecting mantle would contribute to a high degree of variance in the potential temperature distribution of the mid-Cretaceous.

Increased off-ridge volcanic activity in the oceans as well as energetic volcanic activity in the continents suggests that mantle activity had increased globally and not just at the EPR. The convective mantle process was everywhere more active. We have already discussed the high volcanic productivity affecting oceanic crust off ridge. Volcanic activity affecting the continents was also very high. Evidence of increased volcanic activity affecting the continents are the large number of diamondiferous kimberlites emplaced in continental crust during the mid-Cretaceous [Haggerty, 1994].

Diamond is not a stable form of carbon at temperatures and pressures existing in the upper layers of the lithosphere. Diamond is stable at depths greater than $150 \mathrm{~km}$, deep within the continental lithosphere. To preserve the diamondiferous state of carbon, the intrusion of melt containing diamond must be very fast and must cool very quickly so that the diamondiferous state of carbon does not transform into its stable form for the ambient temperature and pressure.

The emplacement of diamondiferous kimberlites into continental crust involves very explosive intrusions. The em- placement of diamondiferous kimberlites are not unique incidences, but they are coincident with periods of normal and reverse superchron and subchron behavior of the geomagnetic field [Haggerty, 1994]. Therefore phenomena causing the distinctions of the mid-Cretaceous may not be a unique incident in space. Cretaceous age diamondiferous kimberlites are not localized to one area on the globe and hence, we infer from this that the characteristic mantle activity of the mid-Cretaceous was not unique to the Pacific plate.

The observations of our study concern only the effects of mantle convection on oceanic crust. Evidence that mantle activity under the continents was different during the midCretaceous also exists. The argument that mantle convection was more rapid during the mid-Cretaceous is a possible explanation for the distinguishing features observed in this study as well as for the presence of diamondiferous kimberlites, midCretaceous in age, in continental crust.

\section{Conclusions}

We have examined changes in the mantle's potential temperature distributions determined from residual depth anomalies in the Pacific basin to infer variations in mantle convection patterns throughout time. The potential temperature distribution of the mid-Cretaceous (83-124 Ma) shows that a larger proportion of the crust in the Pacific basin (midCretaceous in age) has been affected by high potential temperatures than the crust in the Pacific basin younger than the midCretaceous. The mantle potential temperature distribution of the mid-Cretaceous also has a greater variance than the distribution for the time period after the mid-Cretaceous. We infer that the variations in the temperature distribution for the midCretaceous may be explained by a more rapidly convecting mantle.

Excess buoyancy of high-temperature mantle material can cause an increase in volcanic productivity as well as an increase in mantle convection rates. At off-ridge hot spots, excess buoyancy produces an increase in volcanic productivity. At the ridge, excess buoyancy produces an increase in relief, thereby increasing ridge push and contributing to increased subduction and/or obduction rates. Because of viscous drag forces between the mantle and the crust, subduction may influence overall mantle convection by dragging mantle material along with the subducting slab. The inferences that suggest increased mantle convection, increases in volcanic productivity, and increases in spreading rates occurred simultaneously during the mid-Cretaceous, are consistent with previous studies [Larson, 1976; Smith, 1990].

Faster spreading rates may increase the variance of the mantle potential temperature distribution along the ridge. The greater void at the ridge produced by faster spreading may be filled by unusual mantle sources. The unusual mantle sources of the mid-Cretaceous provide the ridge with mantle material that is both hotter and cooler than mantle material existing at the ridge in post mid-Cretaceous time. The faster spreading rate of the mid-Cretaceous may explain the increase in variance in mantle potential temperature observed in our study.

We have inferred from this study of mantle potential temperature distributions that mantle convection was more active during the mid-Cretaceous. The increase in convection may have been initiated by increased buoyancy of hot upwelling mantle material. The increase in the variance of the mantle po- 
tential temperature, however, was an effect of the increased spreading rate of the mid-Cretaceous which in turn increased mantle convection rates.

Acknowledgments. Thank you to those Lamonters who made the final publication of this paper possible. Your support, encouragement and advice have al ways meant a lot to me. LDEO contribution 5435.

\section{References}

Abbott, D., and M. Fisk, Tectonically controlled origin of three unusual rock suites in the Woodlark basin, Tectonics, 5, 1145-1160, 1986.

Cande, S. C., J. L. LaBrecque, R. L. Larson, W. C. Pitman III, X. Golovchenko, and W. F. Haxby, Magnetic Lineations of the World's Ocean Basins, Am. Assoc. of Pet. Geol., Tulsa, Okla., 1989.

Cazenave, A., K. Dominh, C. J. Allegre, and J.G. Marsh, Global relationship between oceanic geoid and topography, J. Geophys. Res., 91, 11,439-11,450, 1986.

Engebretson, D. C., and A. Cox, Relative motions between oceanic plates of the Pacific basin, J. Geophys. Res., 89, 10,291-10,310, 1984.

Forsyth, D., and S. Uyeda, On the relative importance of the driving forces of plate motions, Geophys. J. R. Astron. Soc., 43, 163-200, 1975.

Fowler, C. M. R., The Solid Earth: An Introduction to Global Geophysics, Cambridge Univ. Press, New York, 1990.

Freund, R. J., and W. J. Wilson, Statistical Methods, 644 pp., Academic, San Diego, Calif., 1993.

Haggerty, S. E., Superkimberlites: A geodynamic diamond window to the Earth's core, Earth Planet. Sci. Lett., 122, 57-69, 1994.

Haxby, W. F., Gravity Field of the World's Oceans, Off. of Nav. Res. Boulder, Colo., 1987.

Hayes, D. E., Age-depth relationships and depth anomalies in the Southeast Indian Ocean and South Atlantic Ocean, J. Geophys. Res., 93, 2937-2954, 1988.

Kido, M., and T. Seno, Dynamic topography compared with residual depth anomalies in oceans and implications for age-depth curves, Geophys. Res. Lett., 21, 717-720, 1994.

Langmuir, C. H., E. M. Klein, and T. Plank, Petrological systematics of mid-ocean ridge basalts: Constraints on melt generation beneath ocean ridges, in Mantle Flow and Melt Generation at Mid-Ocean Ridges, 71, pp. 183-280, AGU. Washington, D. C., 1993.
Larson, R. L., Late Jurassic and Early Cretaceous evolution of the western central Pacific Ocean, J. Geomagn. Geoelectr., 28, 219-236, 1976.

Larson, R. L., Geological consequences of superplumes, Geology, 19, 963-966, $1991 \mathrm{a}$.

Larson, R. L., Latest pulse of Earth: Evidence for a mid-Cretaceous superplume, Geology, 19, 547-550, $1991 \mathrm{~b}$.

McKenzie, D., and M. J. Bickle, The volume and composition of melt generated by extension of the lithosphere, J. Petrol., 29, 625-679, 1988.

McNutt, M. K., and M. Fischer, The South Pacific superswell, in Seamounts, Islands, and Atolls, Geophys. Monogr. Ser., vol. 43, edited by B. H. Keating et al., pp. 25-34, AGU, Washington, D. C., 1987.

Muller, R. D., W. R. Roest, J.-Y. Royer, L. M. Gahagan, and J. G. Sclater, A digital age map of the ocean floor, Scripps Inst. of Oceanogr., La Jolla, Calif., 1993.

Mutter, C. Z., and J. C. Mutter, Variations in thickness of layer 3 dominate oceanic crustal structure, Earth Planet. Sci. Lett., 117, 295 317, 1993.

Schubert, G, and D. Sandwell, Crustal volumes of the continents and of oceanic and continental submarine plateaus, Earth Planet. Sci. Lett., 92, 234-246, 1989.

Smith, W. H. F., Marine geophysical studies of seamounts in the Pacific Ocean, Ph.D. thesis, Columbia Univ., New York, 1990.

ten Brink, U. S., and T. M. Brocher, Multichannel seismic evidence for a subcrustal intrusive complex under Oahu and a model for Hawaiian volcanism, J. Geophys. Res., 92, 13,687-13,707, 1987.

West, B. P., J.-C. Sempere, D. G. Pyle, J. P. Morgan, and D. M. Christie, Evidence for variable upper mantle temperature and crustal thickness in and near the Australian-Antarctic Discordance, Earth Planet. Sci. Lett., 128, 135-153, 1994.

White, R. S., D. McKenzie, and R. K. O'Nions, Oceanic crustal thickness from seismic measurements and rare earth element inversions, J. Geophys. Res., 97, 19683-19715, 1992.

K. Ricciardi and D. Abbott, Lamont-Doherty Earth Observatory, Columbia University, Pallisades, NY 10964.

(Received December 27, 1994; revised July 20, 1995; accepted July 24, 1995.) 